Western University

Scholarship@Western

FIMS Presentations

Information \& Media Studies (FIMS) Faculty

2010

Putting the pieces together: Endometriosis blogs, cognitive authority, and collaborative information behaviour

Diane M. Neal

The University of Western Ontario, dneal2@uwo.ca

Pamela J. McKenzie

University of Western Ontario, pmckenzi@uwo.ca

Follow this and additional works at: https://ir.lib.uwo.ca/fimspres

Part of the Communication Commons, and the Library and Information Science Commons

Citation of this paper:

Neal, Diane M. and McKenzie, Pamela J., "Putting the pieces together: Endometriosis blogs, cognitive authority, and collaborative information behaviour" (2010). FIMS Presentations. 29.

https://ir.lib.uwo.ca/fimspres/29 


\author{
Diane M. Neal \\ Faculty of Information and Media Studies, UWO, London, Ontario \\ Pamela J. McKenzie \\ Faculty of Information and Media Studies, UWO, London, Ontario
}

\title{
Putting the pieces together: Endometriosis blogs, cognitive authority, and collaborative information behaviour
}

\begin{abstract}
Endometriosis causes female pelvic pain and infertility. This study examines blogs written by endometriosis patients in the context of collaborative information sharing. Preliminary discourse analysis supported previous studies that found patients questioning medical professionals' cognitive authority. Additionally, the blogger's affective authority may play a role in readers' information judgements.

Résumé : L'endométriose cause chez les femmes des douleurs au pelvis et l'infertilité. Cette étude examine les blogues rédigés par les patientes souffrant d'endométriose dans un contexte d'échange d'information collaborative. L'analyse préliminaire du discours corrobore des études antérieures qui ont démontré que les patientes remettent en question l'autorité cognitive des professionnels de la santé. Par ailleurs, l'autorité affective des blogueuses peut jouer un rôle dans le jugement informationnel des lectrices.
\end{abstract}

\section{Introduction}

This paper describes a preliminary analysis of collaborative information sharing in the context of blogs written by people living with a chronic condition: endometriosis. Collaborative information behaviour (CIB) is a means by which two or more actors communicate to identify, seek, or share information (Talja and Hansen 2006). CIB research aims to observe collaborative activities and behaviours in authentic settings. Although several studies have considered CIB in a number of contexts over the past ten years, most research focuses on workplace rather than on everyday life settings, and few $\mathrm{CIB}$ researchers go beyond the seeking and searching stages to consider the ways in which actors collectively filter, interpret, evaluate, and synthesize as they share (Talja and Hansen 2006).

\section{Context}

One everyday context within which collaboration has been shown to be extremely important for both information sharing and social support is chronic illness. Chronic illness is often broad in scope and effect, difficult to diagnose, complex and ever-changing, and not amenable to conventional medical treatments. It often has significant physical, emotional, and social repercussions, and its management requires significant work by the 
ill person and those around them, much of which may require considerable time and energy, be mentally and emotionally demanding, and occur beyond doctors' offices (Hogan and Palmer 2005). For these reasons, "information work" in chronic illness has received substantial attention from LIS researchers in recent years (Hogan and Palmer 2005, Rubenstein 2009, Souden 2009, Veinot 2009).

Endometriosis is an enigmatic, chronic disease that causes uterine tissue implantation in areas other than the uterus. Highly under diagnosed, it may affect up to $25 \%$ of reproductive-age women. Symptoms vary widely; the most frequent complaint is pelvic pain, and it is a common infertility cause. The broad spectrum of presentation and symptoms, as well as the absence of satisfactory treatments, leave patients seeking information perceived as reliable (Ballweg 2005). Whelan (2007) characterizes women with endometriosis who work together to find answers an "epistemological community" (p. 957).

Both Hogan and Palmer (2005) and Baker (1996) found that a major barrier expressed by people living with chronic illness such as endometriosis was the difficulty in finding information that specifically applied to their situation. As do information seekers in other contexts, people living with chronic illness tend first to seek help or information from interpersonal sources, especially from people like themselves (Harris and Dewdney 1994). Peers within an information seeker's social network who are living with the same disease can provide socially appropriate opportunities in which a seeker may be exposed to disease-relevant information. In addition, peer sources may offer a particularly relevant kind of validation for information from other sources (Veinot 2009), based on experiential rather than biomedical knowledge (Schubert and Borkman 1994). The sharing of information with peers, friends, family, and health providers may additionally provide the social support seekers expect (Veinot 2009, Harris and Dewdney 1994).

Internet resources such as discussion forums and peer-authored blogs have many of the advantages of face-to-face peer sources without the attendant stigma that may be attached to approaching a peer with a personal question (Veinot 2009). Blogs authored by people living with chronic illness are of particular interest to LIS researchers. First, these blogs are a potential source of consumer health information that has been overlooked by researchers. Second, peer blogs provide a naturalistic data source on peer selection, justification, evaluation, and interpretation of information identified by the blogger from other sources. Finally, comments posted to blogs, as well as hyperlinks between the blog and other sources, provide evidence of the functioning of what Talja and Hansen (2006, p.125) call a "community of sharing," a group of people, in this case operating online and perhaps unknown to one another face-to-face, who develop shared understandings and create knowledge structures that may in turn be used by others. As Kjellberg (2009) argues, these features of blogs provide the opportunity for both members and nonmembers of epistemic cultures to interact in dialogue and to participate in the culture. Blogs therefore offer the possibility of extending the face-to-face social networks that 
Veinot (2009) has shown mediate information validation.

\section{Methodology}

Our approach considers how information sharing is embedded in social practices (Talja and Hansen 2006). We therefore begin from the perspective that what constitutes common practice (including what constitutes a good information source) originates not within the head of an individual seeker, but among community members (Talja and McKenzie 2007). Practices such as framing information needs and evaluating information sources therefore always rest on a heterogeneous system of social relationships and involve tacit knowledge of the conventions and procedures shared and developed by practitioners (Talja and Hansen 2006).

For this paper, we focus on a small purposive sample of endometriosis blogs authored by women with the disease as an avenue for collaborative information validation (Veinot 2009). A discursive approach (Talja and McKenzie 2007) permits the analysis of the discursive constructions of previously received or sought information and how these constructions are put to use in talk or writing (Tuominen and Savolainen 1997). Specifically, we employ the discourse analytic techniques developed by Potter (1996) to analyze how blog authors and commenters make and challenge cases for the authority of utilized information sources, such as experiential knowledge, interpersonal sources, or documentary sources (McKenzie 2003). Potter's approach requires close study of the details of actual language use and the construction of accounts, both within and across instances, to identify both the discursive building blocks ("interpretative repertoires") writers and speakers use when producing an account and the discursive functions that account might be serving. It permits the identification of the discursive building blocks bloggers use to represent information sources and the systems of authority that underpin them (e.g., biomedical and experiential). The analysis thereby makes it possible to identify coherent patterns that exist across bloggers and that provide evidence of broader community practices, procedures, and conventions within which CIB operates in this context.

\section{Findings}

Bloggers presented themselves both as information seekers and as information providers, turning to the blogging community with questions as well as reporting their own experiences and summarizing published reports from the popular press as well as medical journals.

As McKenzie (2003) and Oliphant (2009) have found in studies of other health information seekers, endometriosis bloggers made and disputed claims about the cognitive authority of both experiential and biomedical forms of knowledge and of their associated information sources. Two interpretative repertoires underlay many of these cases. The first relied on an understanding of endometriosis as so idiosyncratic that one woman's experience may be completely different from anyone else's. This repertoire strengthened 
critiques of one-size-fits-all sources and justified information seekers' strategies of searching out other women whose symptoms and situations were similar to theirs. The second was built on a concern about the role and interests of the pharmaceutical industry in driving endometriosis research and treatment. The suggestion that individual doctors might be in the thrall of big pharma was a very effective strategy for scrutinizing and possibly undermining biomedical perspectives that might otherwise be unassailably authoritative. Together, these two repertoires presented the woman with endometriosis as needing to advocate for herself, and supported the active seeking and sharing of information as part of this advocacy.

In addition, however, we found that bloggers made and contested claims for the affective authority of information sources. Affective authority claims were made on different bases than cognitive authority claims. First, social context played a crucial role, and sources with long-term and/or intimate knowledge of the blogger's context was presented as providing more personal and therefore more emotionally supportive information. Second, bloggers identified the similarity of the situation as a criterion for a source's affective authoritativeness. This aspect was most evident in discussions of women attempting to become pregnant: when they were successful, the stories of other pregnant women were described as supportive. When they experienced pregnancy loss, the same colleagues lost their affective authority and their stories were no longer valued as informative or supportive. Finally, aesthetic and spiritual components played into descriptions of affective authority: affectively authoritative sources were described as speaking or writing beautifully and bloggers highlighted their ability to comfort or inspire.

\section{Conclusion}

While lay-authored health blogs and other sites for collaborative information behaviour may not meet librarians' traditional standards for authority, they may provide both the social support and the affectively authoritative and situationally relevant information that information seekers may value (Neal, 2010). For example, Rubenstein found that postings in breast cancer discussion forums found that postings provided very detailed accounts of users' personal illness experiences, including related emotional states. Our very preliminary analysis takes a further step in the developing study of affective elements of information behaviour (Nahl and Bilal, 2007). Future research plans include talking with readers and authors of blogs to gain an understanding of how they relate to them as information sources.

\section{References}

Baker, Lynda M. 1996. A study of the nature of information needed by women with Multiple Sclerosis. Library and Information Science Research, 18, 67-81.

Ballweg, Mary Lou. 2005. Endometriosis: The complete reference for taking charge of your health. McGraw-Hill: New York. 
Foster, Jonathan. 2006. Collaborative information seeking and retrieval. Annual Review of Information Science and Technology. ed Blaise Cronin, 329-56 . Vol. 40. Medford, NJ: Information Today.

Harris, Roma M., and Patricia Dewdney. 1994. Theory and research on information seeking. In Barriers to information: how formal help systems fail battered women, eds. Roma Harris and Patricia Dewdney. Westport, Conn.: Greenwood.

Hogan, Timothy P., and Carole L. Palmer. 2005. "Information Work" and chronic illness: Interpreting results from a nationwide survey of people living with HIV/AIDS. Proceedings of the American Society for Information Science and Technology 42(1): 150-169.

Kjellberg, Sara. 2009. Scholarly blogging practice as situated genre: an analytical framework based on genre theory. Information Research 14(3): paper 410. [Available from 21 August, 2009, at http://InformationR.net/ir/143/paper410.html]

McKenzie, Pamela J. 2003. Justifying cognitive authority decisions: Discursive strategies of information seekers. Library Quarterly 73(3): 261-288.

Nahl, Diane, and Dania Bilal. 2007. Information and emotion: the emergent affective paradigm in information behaviour research and theory. Information Today, Inc.: Medford, NJ.

Neal, Diane. 2010. The conundrum of providing authoritative online consumer health information: Current research and implications for information professionals. ASIS\&T Bulletin 36(4): 33-37.

Oliphant, Tami. 2010. "I am making my decision on the basis of experience": constructing authoritative knowledge about treatments for depression. Canadian Journal of Information and Library Science 33(3/4): 215-232.

Potter, Jonathan. 1996. Representing reality: Discourse, rhetoric and social construction. Thousand Oaks, CA: Sage.

Rubenstein, Ellen. 2009. Dimensions of information exchange in an online breast cancer support group. Proceedings of the American Society for Information Science and Technology 46.

Schubert, Marsha A., and Thomasina Borkman. 1994. Identifying the experiential knowledge developed within a self-help group. Understanding the self-help organization: frameworks and findings, ed. Thomas J. Powell. Thousand Oaks, 


\section{CA: Sage.}

Souden, Maria. 2009. Information work in the chronic illness experience. Proceedings of the American Society for Information Science and Technology 45.

Talja, Sanna, and Preben Hansen. 2006. Information sharing. New directions in human information behavior, eds. Amanda Spink and Charles Cole. Dordrecht: Springer.

Talja, Sanna, and Pamela J. McKenzie. 2007. Editors' introduction: special issue on discursive approaches to information seeking in context. Library Quarterly 77(2): 97-108.

Tuominen, Kimmo, and Reijo Savolainen. 1996. A social constructionist approach to the study of information use as a discursive action. Information seeking in context: Proceedings of an international conference in information needs, seeking and use in different contexts, eds. Pertti Vakkari, Reijo Savolainen, and Brenda Dervin.. London: Taylor Graham.

Veinot, Tiffany C. 2009. Interactive acquisition and sharing: Understanding the dynamics of HIV/AIDS information networks. Journal of the American Society for Information Science and Technology 60(11): 2213-2332.

Whelan, Emma. 2007. "No one agrees except for those of us who have it": Endometriosis patients as an epistemological community. Sociology of Health \& Illness 29(7): 957-982. 